\title{
Assessing Intra-Firm Market Knowledge Transfer: The Mediating Roles of Trustworthiness of Source and Perceived Value of Shared Common Knowledge
}

\author{
Sirisuhk Rakthin
}

\begin{abstract}
Market knowledge is one of the most critical resources for a firm's success in business competition nowadays. A challenging point of managing market knowledge is that many firms fail to acquire, to disseminate, and to integrate market knowledge collected from or by the front-line units (e.g., marketing, sales, customer service) into the general market intelligence systems within the organizational body. The study provides insights to existing literature because it empirically examines how trustworthiness of a source and perceived value of shared common knowledge mediate a relationship between ties, motivation, supportive corporate culture, inter-departmental relationship, and a transfer of knowledge in marketing context. Using structural equation modelling, hypotheses were tested among 153 senior executives and middle-level managers in Thailand.
\end{abstract}

Index Terms-Corporate culture, inter-departmental relationship, market knowledge transfer, motivation, perceived value of shared common knowledge, personal ties, trustworthiness of a source.

\section{INTRODUCTION}

The ability to transfer knowledge effectively among individuals is critical to a host of organizational processes and outcomes [1], [2]. According to some scholars, the ability to transfer and use market knowledge represents a distinct source of competitive advantage for organizations [3], [4]. Managers often obtain market knowledge formally (e.g., monthly reports, sales meeting) and informally (e.g., hall talk, telephone phone conversation, e-mail) from various personal and published sources.

Informal interpersonal knowledge and information transfer are thought to play an important role in the knowledge transfer process [1], especially when considering a transfer of market knowledge within the organization.

Several studies extensively examined the relationship between informal networks and knowledge transfer; yet, despite unique characteristics of market knowledge which comprise explicit and tacit knowledge and are very sensitive and critical to corporate advantage and competitive strategy, several organizational and individual conditions encourage or support a transfer of intra-firm market knowledge. In this study, structural equation analysis was employed to analyze relationships among four antecedents-ties, motivation, supportive corporate culture, inter-departmental relationship — and an extent of market knowledge transfer. More importantly, this research study examines the impact

Manuscript received January 9, 2016; revised March 12, 2016

S. Rakthin is with the College of Management, Mahidol University, Bangkok, 10400 Thailand (e-mail: sirisuhk.rak@ mahidol.ac.th). of two potential mediators - trustworthiness of a source and perceived value of shared common knowledge-on the extent of market knowledge transfer within an organization.

The hypotheses were tested among participants in two largest private banks in Thailand (in terms of a number of total assets in 2014). Targeted respondents were executives and middle-level managers involved in front-line tasks (e.g., sales, marketing, and customer service) and support tasks (e.g., sales support, technical support, legal, finance, and accounting). The findings support the partially mediating effects of trustworthiness of a source and perceived value of shared common knowledge on a relationship between the focal constructs and an intra-firm transfer of market knowledge.

\section{FOCAL CONSTRUCTS}

\section{A. Market Knowledge Transfer}

Generally, knowledge can be transferred from a source to a recipient through a variety of formal and informal mechanisms. Researchers have found a number of explanations for how the transfer processes occur, including how the organizational and individual factors can facilitate or obstruct them (e.g., [5]-[7]). Since this study intends to examine a transfer of knowledge in a marketing context, their unique characteristics will be of primary focus.

In this study, market knowledge is conceptualized as a combination of competitor and customer intelligence. There are several definitions of competitor and customer intelligence in various dimensions (e.g., [8], [9]). In brief, competitor intelligence could be summarized as the knowledge that enables us to know what competitors have and their competing strategy, while customer intelligence could be considered as the knowledge that enables us to know what the customers need and their buying decision model.

A challenging point for managing an intra-firm market knowledge transfer mechanism is that many firms fail to analyze such knowledge collected from or by the front-line units, e.g., marketing, sales, or customer service personnel, and to integrate this data into the general market intelligence system [10], [11]. Thus, we assess the extent of a transfer of market knowledge between the front-line and support units from the respondents' perception of their dissemination of such knowledge across departmental boundaries, as valuable, timely, and relevant to company's current objectives.

\section{B. Ties and Inter-departmental Relationship}

The strength of an interpersonal connection can also affect a knowledge transfer process either within or across 
firms [12], [13]. Individuals who frequently share communications or have strong emotional attachment with each other are more likely to share knowledge than those who communicate infrequently or who are not emotionally attached [1]. In this study, the assessments of personal ties and inter-departmental relationship are separated to help differentiate the effects on market knowledge transfer.

\section{Motivation}

Reference [14] suggests that a unit with uniquely valuable knowhow is likely to enjoy an "information monopoly" within an organization [6]. In addition, the sender of such knowledge may be unwilling to devote time and resources to support the transfer [2]. However, considering the fact that employees may also possess personal motivation to retrieve the knowledge or, in this case, market knowledge, from the other units in the organization, we have decided to include the respondent's perception of need and value of market knowledge transfer in the research study. We expect that the reciprocal interaction to transfer such knowledge will increase the extent of dissemination within an organization.

\section{Supportive Corporate Culture}

Similar to the personal motivation, the supportive corporate culture is expected to stimulate an intra-firm transfer mechanism of competitor and customer intelligence by increasing the "eagerness to share and help others" [6] and encouraging the sharing knowledge activities either at the individual or group level.

\section{E. Perceived Value of Shared Common Knowledge and Trustworthiness of Source as Mediating Constructs}

The reluctance of some recipients to accept the knowledge or information because the source unit is not perceived as reliable, trustworthy, or knowledgeable, has long been widely accepted among research scholars [2], [15] Lack of trust in a source of knowledge may reduce the motivation to receive and/or validate information from that source. Furthermore, advice and examples from such source are likely to be challenged and resisted [2], [16]. Previous study evidently supported the role of trust for interpersonal knowledge transfer since the trustworthiness of a source could send a value signal to a recipient and encourage them to acquire knowledge from the source [17]. However, since most market knowledge are likely to be collected by sales or marketing personnel in the field, the recipient's perception of source credibility could become even more crucial. As [18] noted, since the prime interest of salespeople is making sales, they may not be objective observers or reporters of reliable information. Thus, we expect that the recipient's perception of trustworthiness of source will mediate a relationship between personal ties, motivation, interdepartmental relationship, supportive corporate culture and the extent of market knowledge transfer within a firm.

In addition, the degree to which the sender and the recipient share common knowledge is expected to have a positive effect on knowledge and information transfer since it will be easier for an individual to accumulate knowledge in the areas in which he or she has made prior investments [1]. However, to our current knowledge, no research study has examined the effect of the sender's perception of benefit and necessity of sharing common knowledge on the relationship between personal ties, motivation, interdepartmental relationship, and supportive corporate culture and the extent of market knowledge transfer. We expect that the sender's perceived value of shared common knowledge will mediate such relationships.

Therefore, the overarching framework developed in this section can be translated into the following hypotheses:

H1: Positive relationships exist between strong ties of front-line and support personnel, personal motivation, interdepartmental relationship, supportive corporate culture and the perceived value of shared common knowledge.

$\mathrm{H} 2$ : Positive relationships exist between strong ties of front-line and support personnel, personal motivation, interdepartmental relationship, supportive corporate culture and the trustworthiness of a source.

H3: The perceived value of shared common knowledge mediates relationships between strong ties of front-line and support personnel, personal motivation, inter-departmental relationship, supportive corporate culture and the extent of market knowledge transfer.

H4: Trust worthiness of a source mediates relationships between strong ties of front-line and support personnel, personal motivation, inter-departmental relationship, supportive corporate culture and the extent of market knowledge transfer.

\section{METHOD}

\section{A. Samples and Data Collection}

Data were collected from respondents in two largest Thai private banks, in terms of a number of total assets in 2014. The authors developed an instrument to assess the focal and mediating constructs as described earlier. The instrument was evaluated initially by interviewing top business executives, senior executives, and middle-level managers in each bank. In each interview, the respondents were asked to fill out the survey in the presence of the researcher and raise questions as problems or any ambiguities arose. After the first 10 interviews, a new survey was drafted professionally. Then, a pre-test study was conducted by interviewing a new group of senior executives and middle-level managers in each bank $(\mathrm{N}=30)$. The responses from the pre-test significantly assist the researcher in understanding (a) nature of existing workflow among front-line and support units, (b) competitive environments in the industries, and (c) executive's opinion towards a transfer of market knowledge between front-line and support units in each bank.

After the pre-test, a total number of 401 refined surveys were sent to the respondents. Targeted respondents are senior executives and middle-level managers who are involved in front-line tasks (e.g., sales, marketing, and customer service) and support tasks (e.g., sales support, technical support, legal, finance, and accounting). The respondents were informed that the survey was for both educational and managerial purposes and that their responses would be anonymous. A total of 153 responses were returned, with a response rate of $38.15 \%$.

The procedures recommended by [19] for survey translations across different languages were applied before the pre-test study. It is important to stress that this research 
study elicited perceptions of the personnel who were strongly involved in a market knowledge transfer process. As the researcher intended to model managerial behaviour, it may be more appropriate to focus on perceived rather than actual situations [20].

\section{B. Measures}

Twenty-eight measures are used to capture seven latent constructs. All of the exogenous and endogenous measures were adapted from a variety of well-validated sources. Several techniques were used in the survey design to decrease the potential for halo effects, including a use of a variety of measurement scales, grouping together items designed to measure a single construct, and spatially separating the items for various constructs. In a survey, the questions include two different types of scale-Likert-scaled and semantic differential. Due to limited space in the conference proceedings, details of all measurement items including all tables and figures in this paper cannot be presented here. Please contact the author directly for more information.

\section{RESULTS}

\section{A. Measurement Model}

According to [21], a two-step approach was used in testing structural equation models. This approach is particularly salient when using structural equation modelling to assess construct validity since it is essential to identify potential sources of misfit so that researchers can reach consensus on a well-established construct measure before testing substantive research questions. Therefore, the measurement model will be tested and followed by a simultaneous test of the measurement model and the structural model.

As recommended by [22] and [23], a confirmatory factor analysis (CFA) was conducted to assess the measurement model. All indicators were restricted to load on one factor to which they are supposed to measure so as to reflect the hypothesized simple structure of the measurement model [24], [25]. However, LM Test was used to examine whether the restrictions imposed on the model were valid. Factor variances were constrained to equal one to set the metric of the latent variables. In addition, the latent variables were allowed to covary freely to consider the validation of this measurement model. The overall fit indices obtained in EQS [26] were closed to admissible range $\left(\chi_{2}=530.32(d f=313)\right.$, $p=0.00, \mathrm{CFI}=0.97, \mathrm{GFI}=0.83$, and $\mathrm{RMSEA}=0.058$ with $90 \%$ confidence interval $0.049-0.067$ ).

To test for a reliability of all measurement scales in the model, composite reliability or CR [27] is used to examine the internal consistency of a measurement scale. $\mathrm{CR}$ is considered to be a closer approximation to reliability than coefficient alpha [28]. Internal consistency reliabilities for most measurement scales in a model were found to be above commonly accepted standards (CR > 0.7). Reference [29] suggests that reliability is also an indicator of convergent validity and that high construct reliability indicates the existence of internal consistency.

In addition, the high factor loadings of each indicator and high coefficient average variance extracted or AVE ( $>0.5$ in all cases, and in most cases >0.7) also indicate high convergent validity. Furthermore, since construct validity is proved through establishment of convergent and discriminant validities, the procedure suggested by [30] is frequently used to test discriminant validity. According to this procedure, the square root of the coefficient average variance extracted or AVE for a given construct should be larger than any correlation between that construct and the other constructs. This result reveals good discriminant validity. Thus, we can conclude that each latent construct explains its item measures better the other constructs or, in other words, individual measured items also represent only one latent construct in the model.

\section{B. Testing the Hypothesized Structural Model}

The hypothesized structural model was tested using EQS [26]. Residual analysis supported multivariable normality assumptions and revealed that there are no influential outliers. ML (Maximum Likelihood) estimation procedures are employed. The overall fit indices were close to acceptable range $(\chi 2=503.22$, df $=313, \mathrm{p}=0.00, \mathrm{CFI}=$ $0.97, \mathrm{GFI}=0.83$, and RMSEA $=0.058$ with $90 \%$ confidence interval $0.049-0.067$ ). Following the proposed conceptual model, we first discuss the links between the four antecedents and the mediators, and then the effects of the mediators on such paths.

H1 states the positive relationships between strong ties of front-line and support personnel, personal motivation, interdepartmental relationship, supportive corporate culture and the perceived value of shared common knowledge. The empirical results afford mixed support for this hypothesis. Ties, motivation, and supportive corporate culture significantly predict the extent of the perceived value of shared common knowledge $(\beta=0.195, \mathrm{p}<0.01 ; \beta=0.289$, $p<0.01 ; \beta=0.245, p<0.01$, respectively). However, the inter-departmental relationship does not predict the perception of benefit and necessity of sharing common knowledge $(\beta=-0.082$, n.s.). Thus, we conclude that the results partially support $\mathrm{H} 1$.

$\mathrm{H} 2$ states that positive relationships exist between strong ties of front-line and support personnel, personal motivation, inter-departmental relationship, supportive corporate culture and the trustworthiness of a source. As theorized, motivation, inter-departmental relationship, and supportive corporate culture predict the extent of trustworthiness of source $(\beta=$ $0.382, p<0.01 ; \beta=0.252, p<0.01 ; \beta=0.330, p<0.01$, respectively). However, the personal ties does not predict trustworthiness of a source $(\beta=-0.098$, n.s. $)$, thus H2 is partially supported.

The results indicate a significant relationship between perceived value of shared common knowledge and the extent of market knowledge transfer $(\beta=0.465, p<0.01)$. Likewise, a positive relationship exists between trustworthiness of source and the extent of market knowledge transfer $(\beta=0.337, p<0.01)$. Therefore, we can conclude that perceived value of shared common knowledge mediates relationships between ties, motivation, supportive corporate culture, and a transfer of market knowledge, while trustworthiness of a source mediates relationships between motivation, inter-departmental ties, supportive corporate 
culture, and a transfer of market knowledge. Thus, H3 and $\mathrm{H} 4$ are also partially supported.

In addition, we also found a significant relationship between supportive corporate culture and a transfer of market knowledge $(\beta=0.330, p<.01)$. So, it can be concluded that both perceived value of shared common knowledge and trustworthiness of a source partially mediate a relationship between supportive corporate culture and a market knowledge transfer. We also conduct the hypothesized structural model without residual covariation within a set of indicators and across latent variables (unconstrained model). There are no significant differences in structural elements (paths) between unconstrained and constrained model. Since the key concern in the hypothesized model is the mediating role of perceived value of shared common knowledge and trustworthiness of a source in determining the extent of market knowledge transfer, it is logical to test whether the deletion of some mediation paths will significantly improve the model fit.

\section{DISCUSSION}

This research represents one of only a few empirical examinations of mediating effects of perceived value of shared common knowledge and trustworthiness of a source on relationships between the focal antecedents and a transfer of market knowledge. There are a number of reasons that the unique characteristics of market knowledge including the nature of front-line personnel will shape an intra-firm transfer mechanism of market knowledge. For example, the recipients may be reluctant to accept the received market knowledge if the source unit is not perceived as reliable, trustworthy, or knowledgeable [2], [15]. Also, suggestions from such source are likely to be challenged and resisted [2], [16]. In addition, based upon the results of the interview during the pre-test study, most of the managers who were in the support units believe that front-line personnel may not be willing to report or share information or knowledge or even intentionally keep some parts of market information to themselves, especially when they expect that a conflict of interest may occur as a result of sharing such knowledge. The concept of agent-principal relationship and intrinsic motivation in agency theory could be applied in this case [31]. Thus, the empirical results suggest that trustworthiness of a source mediates relationships between these antecedents - (a) inter-departmental relationship, (b) supportive corporate culture, and (c) personal motivation - and the extent of market knowledge transfer between the front-line and the support personnel. It is logical to acknowledge that trustworthiness of a source does not mediate a relationship between personal ties and market knowledge transfer since the strong personal ties between front-line and support personnel could reduce the recipient's suspicion of whether the source of such knowledge is unreliable. Personal ties between recipients and senders can influence a knowledge transfer process within an organization. This notion is empirically supported by the findings in this study.

Furthermore, two mediators illustrates that the flow of knowledge between senders and recipients can be affected by cognitive and relational factors. Trustworthiness of a source can be considered a social and relational mediator. In addition, a perceived value of shared common knowledge represents cognitive perspective of knowledge transfer mechanisms. The empirical results of this study also demonstrate that sharing cognitive map between senders and recipients is the critical path of knowledge transfer.

\section{REFERENCES}

[1] R. Reagans and B. McEvily, "Network structure and knowledge transfer: The effects of cohesion and range," Administrative Science Quarterly, vol. 48, pp. 240-267, 2003.

[2] G. Szulanski, "Exploring internal stickiness: Impediments to the transfer of best practice within the firm," Strategic Management Journal, vol. 17, pp. 27-43, 1996.

[3] A. Menon and P. R. Varadarajan, "A model of marketing knowledge use within firms," Journal of Marketing, vol. 56, no. 4, pp. 53-71, 1992.

[4] E. Maltz and A. "Kohli, market intelligence dissemination across functional boundaries," Journal of Marketing Research, vol. 33, pp. 47-61, 1996.

[5] S. T. Cavusgil, R. J. Calantone, and Y. Zhao, "Tacit knowledge transfer and firm innovation capability," Journal of Business \& Industrial Marketing, vol. 18, no. 1, pp. 6-21, 2003.

[6] A. K. Gupta and V. Govindarajan, "Knowledge flows within multinational corporations," Strategic Management Journal, vol. 21, pp. 473-496, 2000.

[7] I. Nonaka, "A dynamic theory of organizational knowledge creation," Organization Science, vol. 5, no. 1, pp. 14-37, 1994.

[8] S. Kelly, Customer Intelligence: From Data to Dialogue, Chichester: Wiley, 2006.

[9] S. Wright, W. D. Pickton, and J. Callow, "Competitive intelligence in UK firms: A typology," Marketing Intelligence and Planning, vol. 20, no. 6, pp. 349-360, 2002.

[10] T. A. Festervand, S. J. Grove, and R. E. Reidenbach, "The sales force as a marketing intelligence system," The Journal of Business and Industrial Marketing, vol. 3, no. 1, pp. 53-59, 1988.

[11] K. L. Meunier-FitzHugh and N. F. Piercy, "Integrating marketing intelligence sources," International Journal of Market Research, vol. 48, no. 6, pp. 699-719, 2006.

[12] M. Granovetter, "The strength of weak ties," American Journal of Sociology, vol. 6, pp. 1360-1380, 1973.

[13] M. T. Hansen, "The search-transfer problem: The role of weak ties in sharing knowledge across organization subunits," Administrative Science Quarterly, vol. 44, pp. 82-111, 1999.

[14] R. M. Cyert, "Management of knowledge," Keynote Address at the Carnegie Bosch Institute's 1995 International Conference on High Performance Global Corporations. Excerpted in Global View, Newsletter of the Carnegie Bosch Institute for Applied Studies in Management, The Carnegie Mellon University, 1995.

[15] G. Zaltman, R. Duncan, and J. Holbeck, Innovations and Organizations, New York: Wiley, 1973.

[16] R. E. Walton, "The diffusion of new work structures: Explaining why success didn't take," Organizational Dynamics, pp. 3-21, Winter, 1975.

[17] T. Pacharapha and V. V. Ractham, "Knowledge acquisition: The roles of perceived value of knowledge content and source," Journal of Knowledge Management, vol. 16, no. 5, pp. 724-739, 2012.

[18] C. Moss, "Industrial salesmen as a source of marketing intelligence," European Journal of Marketing, vol. 13, no. 3, pp. 94-102, 1979.

[19] R. W. Brislin, "Applied cross-cultural psychology: An introduction," in R. W. Brislin, Ed. Applied Cross-Cultural Psychology, Newbury Park, CA: Sage, 1990.

[20] K. Weick, The Social Psychology of Organizing, Boston: Addison Wesley Publishing Company, 1969.

[21] J. C. Anderson and D. W. Gerbing. "Structural equation modeling in practice: A review and recommended two-step approach," Psychological Bulletin, vol. 103, no. 3, pp. 411-423, 1988.

[22] K. A. Bollen, Structural Equations with Latent Variables, John Wiley \& Sons, Inc, 1989

[23] J. C. Nunnally, Psychometric Theory, New York: McGraw-Hill, 1978.

[24] L. L. Thurston, "Experimental study of simple structure," Psychometrics, vol. 5, pp. 153-168, 1940.

[25] D. Kaplan, Structural Equation Modeling: Foundations and Extensions, Sage Publications, 2000.

[26] P. M. Bentler, EQS 6 Structural Equations Program Book, Encino, CA: Multivariate Software, Inc., 2004.

[27] C. E. Werts, R. L. Linn, and K. G. Jöreskog, "Interclass reliability estimates: Testing structural assumptions," Educational and Psychological Measurement, vol. 34, no. 1, pp. 23-33, 1974. 
[28] W. W. Chin, "The partial least squares approach to structural equation modeling," Modern Methods for Business Research, Hillsdale, NJ: Lawrence Erlbaum Associates Inc., pp. 295-336, 1998.

[29] J. F. Hair, W. Black, B. Babin, R. E. Anderson, and R. Tatham, Multivariate Data Analysis, $6^{\text {th }}$ edition, Englewood Cliffs, NJ: Prentice Hall, 2007.

[30] C. Fornell and D. F. Larcker, "Structural equation models with unobservable variables and measurement error: Algebra and statistics," Journal of Marketing Research, vol. 18, no. 3, pp. 382-388, 1981.
[31] M. K. Eisenhardt, "Agency theory: An assessment and review," Academy of Management Review, vol. 14, no. 1, pp. 57-74, 1989.

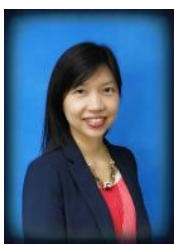

Sirisuhk Rakthin is a $\mathrm{PhD}$, a lecturer at the College of Management, Mahidol University in Bangkok, Thailand. Formerly she was a marketing director with a leading multinational telecom service provider. She earned her doctoral degree in marketing with specialization in knowledge management and strategy from Michigan State University. 